\title{
Marginal zone lymphomas in children and the young adult population; characterization of genetic aberrations by FISH and RT-PCR
}

\author{
Kathryn A Rizzo ${ }^{1,4}$, Berthold Streubel ${ }^{2}$, Stefania Pittaluga ${ }^{1}$, Andreas Chott ${ }^{3}$, Liqiang $\mathrm{Xi}^{1}$, \\ Mark Raffeld ${ }^{1}$ and Elaine S Jaffe ${ }^{1}$ \\ ${ }^{1}$ Hematopathology Section, Laboratory of Pathology, Center for Cancer Research, National Cancer Institute, \\ National Institutes of Health, Bethesda, MD, USA; ${ }^{2}$ Department of Pathology, Medical University of Vienna, \\ Vienna, Austria and ${ }^{3}$ Department of Pathology, Vienna General Hospital, Vienna, Austria
}

\begin{abstract}
Marginal zone lymphomas present rarely in children and young adults as either primary nodal or extranodal disease and have an excellent prognosis. To date, chromosomal aberrations have not been analyzed in the pediatric and young adult population. We undertook a study to analyze genetic alterations in nodal and extranodal marginal zone lymphomas in children and young adults using fluorescence in situ hybridization (FISH) and RT-PCR. These findings were correlated with clinical features at presentation and immunophenotype. Forty-one cases were identified meeting these criteria. The age range was $1.5-29$ years old with $49 \%$ of the cases $<18$ years of age. $73 \%$ of the marginal zone lymphoma cases showed evidence of light chain restriction by immunohistochemistry or flow cytometry. CD43 was coexpressed in $83 \% .85 \%$ of the marginal zone lymphoma cases tested showed evidence of immunoglobulin heavy chain gene rearrangement. Fifty-nine percent of the cases were nodal marginal zone lymphomas with a median age at presentation of 16 years and an M/F ratio of 7:1. Twenty-one percent of the nodal marginal zone lymphoma cases contained genetic aberrations. Seventeen percent contained trisomy 18 with one case containing an additional trisomy 3. A translocation of the immunoglobulin heavy chain gene to an unknown partner gene was present in one case. Forty-one percent of the cases were extranodal marginal zone lymphomas with a median age of 24 years and a M/F ratio of 1.4:1. Eighteen percent of the extranodal marginal zone lymphoma cases contained genetic aberrations. The $t(14 ; 18)$ involving the IGH and MALT1 genes was present in one case, tetraploidy was present in one case, and another case contained trisomy 3. Overall the incidence of genetic aberrations in marginal zone lymphomas in the pediatric and young adult population is low, but the aberrations seen are similar to those seen in the adult population. Modern Pathology (2010) 23, 866-873; doi:10.1038/modpathol.2010.63; published online 19 March 2010
\end{abstract}

Keywords: marginal zone lymphoma; pediatric; genetic aberrations

Marginal zone lymphomas are indolent lymphomas thought to arise at the post-germinal center stage of differentiation. They are morphologically and clinically heterogeneous. Three major categories are recognized in the 2008 WHO classification: nodal marginal zone lymphoma, extranodal marginal zone lymphoma of mucosa-associated lymphoid tissue,

Correspondence: Dr ES Jaffe, Department of Pathology, Medical University of Vienna, National Cancer Institute, 10 Center Drive, Room 2B 42, Bethesda, MD 20892-1500, USA.

E-mail: elainejaffe@nih.gov

${ }^{4}$ Current address: Department of Pathology and Laboratory Medicine, Indiana University School of Medicine, Indianapolis, IN, USA

Received 30 November 2009; revised and accepted 16 February 2010; published online 19 March 2010 and splenic marginal zone lymphoma. The modifier 'B-cell' as applied to marginal zone lymphoma has been eliminated from standard terminology, as these lymphomas are exclusively of B-cell derivation. ${ }^{1}$ In the adult population, extranodal marginal zone lymphomas (MALT lymphoma) occur more frequently than nodal marginal zone lymphomas, and extranodal marginal zone lymphomas are associated with specific genetic aberrations not present in nodal or splenic marginal zone lymphomas. ${ }^{2,3}$ Unlike other B-cell lymphomas such as follicular lymphoma and mantle cell lymphoma, marginal zone lymphomas lack a specific immunophenotype. Thus, the recognition of specific genetic aberrations might allow for greater diagnostic accuracy, or provide additional prognostic data. A well-documented example is the 
$\mathrm{t}(11 ; 18)(\mathrm{q} 21 ; \mathrm{q} 21)$ in gastric MALT lymphomas. ${ }^{2}$ The presence of this translocation is associated with a lack of regression of the lymphoma upon eradication of $H$. pylori. ${ }^{4,5}$

The extranodal marginal zone lymphomaassociated genetic aberrations also show variable frequency depending on the site of involvement. ${ }^{3,6}$ In the study from Streubel et $a l^{3}$ the $t(11: 18)$ (q21;q21) was most often found in pulmonary MALT lymphomas $(53 \%)$ with an overall prevalence rate of $14 \%$. The $\mathrm{t}(14 ; 18)(\mathrm{q} 32 ; \mathrm{q} 21)$ involving the $I G H$ and MALT1 genes had the highest prevalence in extranodal marginal zone lymphomas of the ocular adnexa $(24 \%)$ with an overall rate of $11 \%$. Trisomies 3 and 18 were shown to have an overall prevalence of 31 and $11 \%$, respectively. Numerical chromosomal abnormalities, particularly gains of chromosome 3, are not specific for extranodal marginal zone lymphomas and can be seen in other B-cell malignancies including nodal marginal zone lymphomas..$^{7-12}$

Nodal marginal zone lymphoma in the pediatric and young adult population is relatively rare, with specific clinicopathological features that led to the delineation of pediatric nodal marginal zone lymphomas as a distinct entity in the 2008 WHO classification. ${ }^{1}$ Extranodal marginal zone lymphoma is rare in children, but otherwise resembles the disease seen in adults. The genetic aberrations seen in marginal zone lymphomas in the adult population have not been analyzed in a large cohort study in the pediatric and young adult age group. The aim of this study was to analyze all available cases of marginal zone lymphoma in the pediatric and young adult age group via RT-PCR and fluorescent in situ hybridization, and to correlate the results with immunophenotypic and molecular features.

\section{Materials and methods}

\section{Case Selection}

We reviewed the files of the Hematopathology section of the Laboratory of Pathology, National Cancer Institute, National Institutes of Health from 1995 to 2006 for cases with a diagnosis of marginal zone lymphoma and age less then 30 years at presentation. All cases were submitted in consultation from outside physicians and the hematoxylin and eosin-stained slides were reviewed. There were 22 newly identified cases, subsequent to the study by Taddesse-Heath et al, ${ }^{13} 12$ of which had material available for genetic studies. 29 cases previously reported had material available for genetic studies and were included in this study.

\section{Immunohistochemistry}

Immunohistochemical studies were performed to confirm the diagnosis of marginal zone lymphoma.
We used fixed paraffin-embedded tissue sections by use of antigen retrieval methods on an automated immunostainer (Ventana Medical System, Tucson, AZ, USA), according to the manufacturer's instruction. The antibodies analyzed included CD20 (L26), CD3, kappa, lambda, BCL-2, BCL-6, IgD (Dako, Carpinteria, CA, USA), CD10 (Novocastra, Newcastle upon Tyne, UK) and CD43 (Becton Dickinson, San Jose, CA, USA). Light chain immunohistochemical staining was scored as showing either light chain restriction, or non-contributory if the neoplastic cells failed to stain for either kappa or lambda. A polytypic pattern was considered as evidence against a diagnosis of lymphoma.

\section{Molecular Studies for Immunoglobulin Gene Rearrangement}

Genomic DNA was extracted from formalin-fixed, paraffin-embedded tissue blocks. In some cases DNA was extracted using standard phenolchloroform methods, whereas in other cases tissue samples were sectioned on charged slides, deparaffinized with xylene, and hydrated before being scraped into polymerase chain reaction (PCR) tubes. The tissues were mixed with Gene Releaser resin (Bioventures, Murfreesboro, TN, USA) and preincubated in a Perkin Elmer 480 thermocycler (Applied Biosystems, Foster City, CA, USA) according to the manufacturer's recommendations. To determine clonality of the immunoglobulin heavy chain gene, PCR was performed as previously described. ${ }^{14}$ Briefly, consensus primers to the conserved framework three (FR3) and the $\mathrm{JH}$ alpha regions of the immunoglobulin heavy chain gene were used in a Master Mix containing LD Taq DNA polymerase (Applied Biosystems) previously treated with Taq Start antibody (Clontech, Palo Alto, CA, USA). Additional seminested PCR amplification was performed using consensus primers to the conserved framework two (FR2) region of the immunoglobulin heavy chain gene, according to the method of Ramasamy et $\mathrm{al}^{15}{ }^{15}$ PCR products were analyzed using polyacrylamide gel electrophoresis as previously described. ${ }^{14}$ Cases negative for immunoglobulin heavy chain gene rearrangement for which paraffin blocks were available were further studied for rearrangements of the IGk locus using the Biomed II primer set described by van Dongen et al (Leukemia 17:2257-2237, 2003), and supplied by InVivoScribe Technologies (IGK Gene Clonality Assay-ABI Fluorescence Detection). These reactions interrogate rearrangements involving the $\mathrm{Vk}$ loci and Jk (Tube A), the Vk locus and the kDE locus (Tube $\mathrm{B}$ ), and the $\mathrm{k}$ intron RSS locus and the $\mathrm{kDE}$ locus (Tube B). The products were analyzed by capillary electrophoresis on an ABI 3130 Genetic Analyzer, and electropherograms were analyzed using GeneMapper software version 3.7 (ABI). 


\section{Detection of $t(11 ; 18)(q 21 ; q 21)$ by RT-PCR}

RNA was isolated from archival formalin-fixed, paraffin-embedded lymphoma tissues. Total RNA was extracted from $10 \mu \mathrm{m}$ sections with a high pure RNA paraffin kit (Roche Diagnostics, Mannheim, Germany). First-strand cDNA was synthesized from $1 \mu \mathrm{g}$ total RNA with a superscript first-strand synthesis system (Invitrogen, Carlsbad, CA, USA) using random hexamers as primers. RT-PCR for the detection of the API2-MALT1 fusion transcript was performed according to Inagaki et al with one modification: first round RT-PCR products were amplified in a second round separately and not as multiplex nested PCRs to discriminate the various fusion signals. ${ }^{16}$ Where indicated PCR products were sequenced using dRhodamine dye terminators on an ABI Prism 310 (PE Applied Biosystems, Foster City, CA, USA).

\section{FISH Analysis}

In all cases formalin-fixed paraffin-embedded tissue was used for FISH and RT-PCR studies. FISH was performed on Interphase cells with the following probe sets: for the detection of the $\mathrm{t}(14: 18)(\mathrm{q} 32 ; \mathrm{q} 21)$ involving IGH and MALT1 P1 artificial chromosome (PAC) 152M5 (SpectrumOrange labeled) spanning the MALT1 gene and flanking regions and bacterial artificial chromosome (BAC) 158A2 were used; for rearrangements of $B C L 10$, BACs RP11-1077C10 and RP11-36L4 centromeric to BCL10 and RP11-1080I1 and RP11-40K4 telomeric to BCL1O were used. Translocations of FOXP1 were investigated with BACs RP11-154H23 and RP11-215K24, RP11-465K1 and RP11-335D10 for CNN3, RP11-79K3 and RP1177E14 for JMJD2C, RP11-13H20 and RP11-14K9 for ODZ2. 4 Aberrations of IGH and BCL6 were examined with dual color break-apart probes (Vysis, Downer's Grove, IL, USA). For the detection of trisomies 3, 12 and 18 we applied centromerespecific probes (Vysis). The cut-off value for the diagnosis of each probe set was the mean percentage of cells with a false-positive signal constellation plus 3 s.d., as assessed on tissue from 20 reactive lymph nodes. Fluorescence in situ hybridization (FISH) procedure was done according to published standard methods. ${ }^{17}$

\section{Results}

\section{Characteristics of Newly Identified Cases}

Twenty-two newly identified cases of marginal zone lymphoma were identified, and the clinical features are summarized in Table 1 . The diagnosis of marginal zone lymphoma was established based on a mature B-cell neoplasm with clonal rearrangement of immunoglobulin genes in 20 of 22 cases. In 1 case PCR studies were negative for immunoglobulin gene rearrangement using FR3 and IgK probes, but no
Table 1 Clinical characteristics and clonality analysis of newly identified marginal zone lymphoma cases

\begin{tabular}{ccclcl}
\hline Case & \multirow{2}{*}{ Age } & Sex & Lymph node/site & IHC & IG \\
\hline \multicolumn{7}{c}{ Nodal } & marginal & zone & lymphoma cases & & \\
1 & 17 & $\mathrm{M}$ & Submental & $\mathrm{K}$ & Clonal \\
2 & 13 & $\mathrm{M}$ & Cervical & $\mathrm{L}$ & Clonal \\
3 & 11 & $\mathrm{~F}$ & Inguinal & $\mathrm{L}$ & Clonal \\
4 & 15 & $\mathrm{~F}$ & Inguinal & $\mathrm{K}$ & Clonal \\
5 & 18 & $\mathrm{M}$ & Cervical & $\mathrm{L}$ & Clonal \\
6 & 14 & $\mathrm{M}$ & Cervical & $\mathrm{NC}$ & Clonal \\
7 & 6 & $\mathrm{M}$ & Axilla & $\mathrm{L}$ & Clonal \\
8 & 17 & $\mathrm{M}$ & Cervical & $\mathrm{K}$ & Clonal \\
9 & 17 & $\mathrm{M}$ & Cervical & $\mathrm{K}$ & Clonal \\
10 & 22 & $\mathrm{M}$ & Cervical & $\mathrm{K}$ & Clonal \\
11 & 16 & $\mathrm{M}$ & Inguinal & $\mathrm{K}$ & Clonal \\
12 & 26 & $\mathrm{M}$ & Submandibular & $\mathrm{K}$ & Polyclonal \\
13 & 29 & $\mathrm{M}$ & Submandibular & $\mathrm{NC}$ & Clonal \\
\multicolumn{7}{c}{} & & & & \\
Extranodal marginal & zone lymphoma cases & & \\
1 & 24 & $\mathrm{M}$ & Soft tissue, scalp & $\mathrm{NC}$ & Clonal \\
2 & 29 & $\mathrm{M}$ & Skin & $\mathrm{K}$ & Clonal \\
3 & 23 & $\mathrm{M}$ & Adenoids & $\mathrm{K}$ & Clonal \\
4 & 1.5 & $\mathrm{~F}$ & Tonsils & $\mathrm{K}$ & Clonal \\
5 & 16 & $\mathrm{M}$ & Soft tissue, head & $\mathrm{K}$ & Clonal \\
6 & 17 & $\mathrm{~F}$ & Skin, arm & $\mathrm{K}$ & Clonal \\
7 & 27 & $\mathrm{M}$ & Skin, back & $\mathrm{K}$ & NA/Poly \\
$8 \mathrm{a}$ & 10 & $\mathrm{M}$ & Conjunctiva, left & $\mathrm{K}$ & Clonal \\
$8 \mathrm{~b}^{\mathrm{c}}$ & 11 & $\mathrm{M}$ & Conjunctiva, left & $\mathrm{K}$ & Clonal \\
9 & 11 & $\mathrm{M}$ & Conjunctiva & $\mathrm{NC}$ & Clonal \\
& & & & \\
\end{tabular}

NP, not performed; K, kappa light chain restriction; L, lambda light chain restriction; NC, non-contributory.

${ }^{\mathrm{a}}$ Light chain evaluation performed via flow cytometry.

${ }^{\mathrm{b}}$ No amplification seen in framework II, framework III and IgK showed no peaks.

${ }^{\mathrm{C}}$ Same patient with a recurrence 1 year later.

amplification was obtained with FR2. Both cases showed monoclonal expression of kappa light chain. The neoplastic cells lacked expression of CD10 and BCL6 in all cases studied. There were 13 cases of nodal marginal zone lymphoma and nine cases of extranodal marginal zone lymphoma. The clinical features were similar to those of our previous series with all patients presenting with a single site of disease (Stage 1). One patient had a recurrence of a conjunctival extranodal marginal zone lymphoma 1 year later.

\section{Clinical and Immunohistochemical Characteristics of Study Cases}

Of the 22 newly identified cases, 12 cases (five nodal, seven extranodal) had sufficient material for further genetic studies. In addition, 29 cases were selected from our previous study ${ }^{13}$ as having adequate material for further genetic studies. The age range in the 41 cases comprising the study cohort was $1.5-29$ years with $49 \%$ of the cases $\leq 18$ years of age. In all, 59\% (24 cases) were nodal marginal zone lymphomas with a median age at presentation of 16 years and an $\mathrm{M}: \mathrm{F}$ ratio of $7: 1$ (Table 2). Sixty-three percent (15 cases) were $\leq 18$ years and consisted only of males. The most 
Table 2 Genetic characterization of nodal marginal zone lymphoma

\begin{tabular}{|c|c|c|c|c|c|}
\hline Case & Age & Sex & $\begin{array}{l}\text { Lymph } \\
\text { node site }\end{array}$ & $R T-P C R$ & FISH \\
\hline 2 & 13 & $\mathrm{M}$ & Cervical & Negative & $\begin{array}{l}\text { Trisomies } \\
3 \& 18\end{array}$ \\
\hline 5 & 18 & $\mathrm{M}$ & Cervical & Negative & Normal \\
\hline 7 & 6 & $\mathrm{M}$ & Axilla & Negative & Trisomy 18 \\
\hline 10 & 22 & $\mathrm{M}$ & Cervical & Negative & Trisomy 18 \\
\hline 11 & 16 & $\mathrm{M}$ & Inguinal & Negative & Normal \\
\hline $14^{\mathrm{a}}$ & 20 & $\mathrm{M}$ & Preauricular & Negative & Normal \\
\hline $15^{\mathrm{a}}$ & 16 & $\mathrm{M}$ & Cervical & NA & Normal \\
\hline $16^{\mathrm{a}}$ & 19 & M & Cervical & NA & Normal \\
\hline $17^{\mathrm{a}}$ & 17 & $\mathrm{M}$ & Submental & Negative & Normal \\
\hline $18^{\mathrm{a}}$ & 22 & $\mathrm{M}$ & Cervical & Negative & Normal \\
\hline $19^{\mathrm{a}}$ & 26 & $\mathrm{~F}$ & Breast & Negative & Normal \\
\hline $20^{\mathrm{a}}$ & 6 & $\mathrm{M}$ & Cervical & NA & Normal \\
\hline $21^{\mathrm{a}}$ & 16 & $\mathrm{M}$ & Cervical & Negative & $\begin{array}{l}\text { t(IGH), } \\
\text { unknown } \\
\text { partner gene }\end{array}$ \\
\hline $22^{\mathrm{a}}$ & 16 & $\mathrm{M}$ & Cervical & Negative & Normal \\
\hline $23^{\mathrm{a}}$ & 16 & $\mathrm{M}$ & Periparotid & NA & Normal \\
\hline $24^{\mathrm{a}}$ & 14 & $\mathrm{M}$ & Cervical & Negative & Trisomy 18 \\
\hline $25^{\mathrm{a}}$ & 25 & $\mathrm{M}$ & Submental & Negative & Normal \\
\hline $26^{\mathrm{a}}$ & 6 & $\mathrm{M}$ & Cervical & Negative & Normal \\
\hline $27^{\mathrm{a}}$ & 24 & $\mathrm{~F}$ & Inguinal & $\mathrm{NA}$ & Normal \\
\hline $28^{\mathrm{a}}$ & 16 & M & Cervical & NA & Normal \\
\hline $29^{\mathrm{a}}$ & 23 & $\mathrm{M}$ & Supraclavicular & Negative & Normal \\
\hline $30^{\mathrm{a}}$ & 15 & $\mathrm{M}$ & Inguinal & Negative & Normal \\
\hline $31^{\mathrm{a}}$ & 23 & $\mathrm{~F}$ & Cervical & Negative & Normal \\
\hline $32^{\mathrm{a}}$ & 15 & $\mathrm{M}$ & Submandibular & Negative & NA \\
\hline
\end{tabular}

${ }^{\mathrm{a}}$ Cases previously reported by Taddesse Heath et al. ${ }^{13}$

Negative, denotes negative for all known breakpoints; NA, tissue not available for analysis.

common location for nodal marginal zone lymphoma was cervical lymph nodes seen in $54 \%$ (13 cases) followed by inguinal lymph nodes in $13 \%$ (three cases) and submental in 8\% (two cases). Co-expression of CD43 was present in 83\% (15 of 18 cases), BCL-2 in $42 \%$ (5 of 12 cases) and IgD in $25 \%$ ( 5 of 20 cases). BCL-6 and CD10 were negative in all cases studied. Evidence of clonality in nodal marginal zone lymphomas was shown via immunoglobulin gene rearrangement in 22 of 24 cases (92\%); the two negative cases had unsuccessful framework 2 amplification (1 case), and insufficient material for kappa probe analysis (1 case). Light chain restriction was shown by immunohistochemistry in 18 of 24 cases (Figure 1), with staining being inconclusive in the remaining six cases.

A total of $41 \%$ (17 cases) were extranodal marginal zone lymphomas (Table 3). The median age at presentation was 24 years, with an age range between 1.5 years and 29 years. The M:F ratio was $1.4: 1$ and $29 \%$ (five cases) were $\leq 18$ years. The most common localization for extranodal marginal zone lymphomas was skin and soft tissue, seen in $35 \%$ (six cases). Co-expression of CD43 was present in $82 \%$ ( 9 of 11 cases), BCL-2 in $43 \%$ (three of seven cases) and IgD in $20 \%$ ( 2 of 10 cases). BCL- 6 and CD10 were negative in all cases studied.
Clonality was shown in $94 \%$ (16 of 17 cases) of the extranodal marginal zone lymphoma cases. Light chain restriction was present in $71 \%$ (12 cases) with lambda light chain restriction identified in only a single case presenting as an orbital mass. Immunoglobulin heavy chain gene rearrangement was present in $75 \%$ (12 of 16 cases). Two of the four negative cases did not have amplifiable DNA for framework 2 studies, and none of the four had additional material available for study with the kappa light chain probes. One case lacked light chain restriction and was negative by PCR, but showed Trisomy 3 by FISH (see below).

\section{Marginal Zone Lymphoma Associated Genetic Aberrations}

RT-PCR and FISH analyses for marginal zone lymphoma-associated genetic aberrations were performed on the 41 cases to detect the following aberrations: $\mathrm{t}(14 ; 18) / I G H-M A L T 1, \mathrm{t}(F O X P 1), \mathrm{t}(B C L 10)$, trisomy3, trisomy18, $\mathrm{t}(O D Z 2), \mathrm{t}(J M J D 2 C)$ and $\mathrm{t}(C N N 3)$ (Figure 1f). ${ }^{18}$ In all, $21 \%$ of the 24 nodal marginal zone lymphomas analyzed contained genetic aberrations (Tables 2 and 4). Trisomy 18 occurred in $17 \%$ (4 of 23 cases), trisomy 3 occurred in $4 \%$ (1 of 23 cases) and a $\mathrm{t}(I G H)$ to an unknown partner gene occurred in $4 \%$ ( 1 of 23 cases). One case contained trisomies 3 and 18. Four of the five positive cases were found in patients less than 18 years of age.

Genetic analysis was successfully performed on 17 cases of extranodal marginal zone lymphomas (Tables 3 and 4). Eighteen percent (three cases) contained genetic aberrations. The $t(14 ; 18)$ involving IGH and MALT1 genes was seen in 1 of 14 cases $(7 \%)$. In one of the cases, which had not shown clonality via immunohistochemistry or immunoglobulin heavy chain gene rearrangement (case 19), trisomy 3 was present. For case 10, analyses on the thyroid and adjacent lymph node were performed. In this case, the adjacent lymph node showed tetraploidy and there was not enough material for FISH analysis on the thyroid specimen. Trisomy 18, which was relatively prevalent in the nodal marginal zone lymphomas, was not identified in the extranodal marginal zone lymphoma cases.

\section{Discussion}

We undertook this study to determine if genetic aberrations associated with marginal zone lymphomas in adults could be identified in similar lymphomas in the pediatric and young adult population. To accomplish these goals we used available paraffin-embedded sections from 12 newly identified cases reviewed in our laboratory, and 29 additional cases previously published. ${ }^{13}$ In addition, we were able to expand and reconfirm our previously reported clinicopathological experience with marginal zone lymphoma in the pediatric 

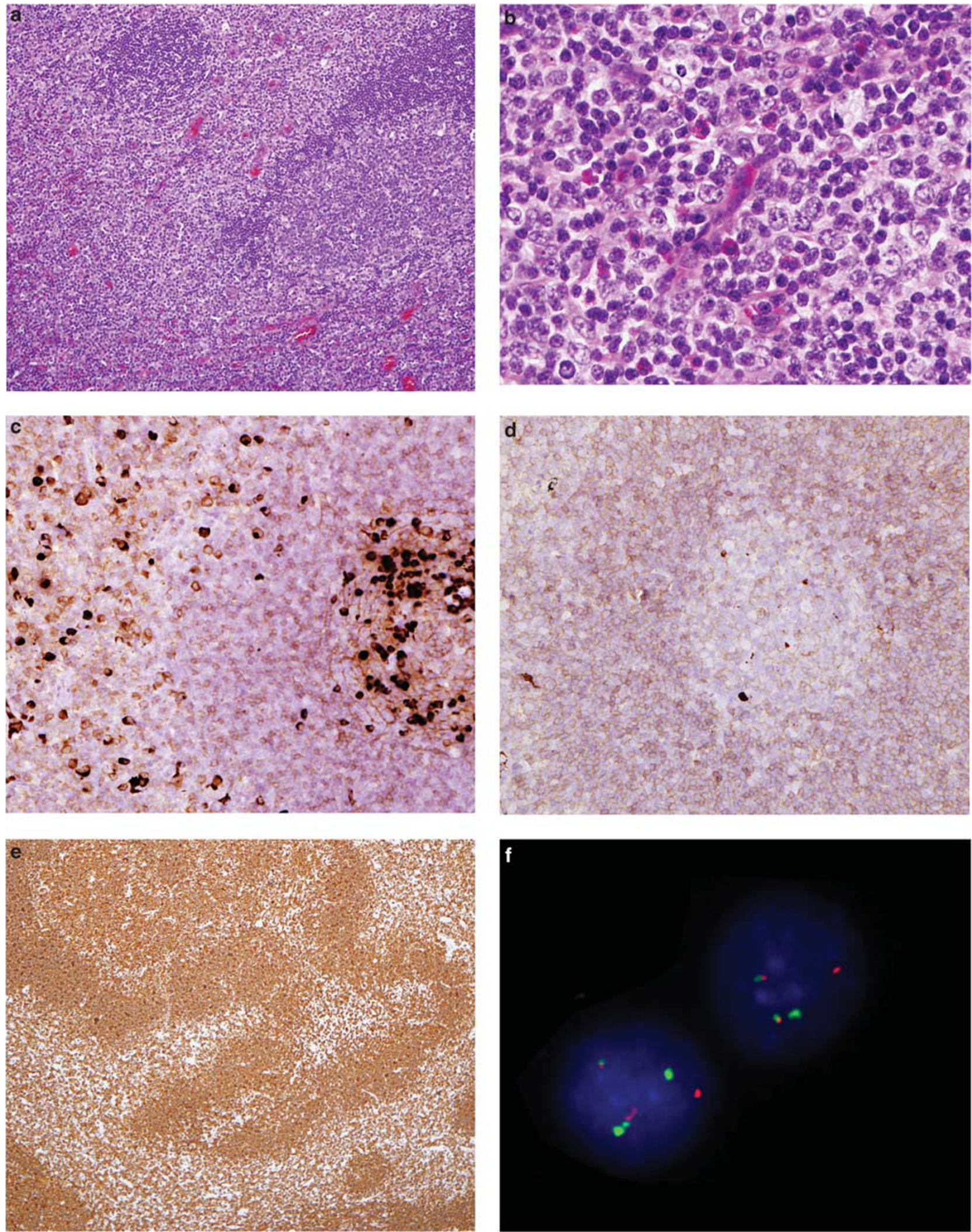

Figure 1 Histology, immunophenotype and FISH of marginal zone lymphoma. (a) H\&E image of nodal marginal zone lymphoma. Residual germinal centers are surrounded by an atypical lymphoid proliferation. Magnification $\times 40$. (b) At higher power lymphoid cells show a spectrum in cell size. Admixed eosinophils are present. Magnification $\times 400$. (c) Atypical B-cells show monotypic staining for lambda light chain by immunohistochemistry. Follicular colonization is present. Magnification $\times 200$. (d) Staining for kappa is negative. Magnification $\times$ 200. (e) CD20 shows diffuse positivity and infiltration of the marginal zone. (f) FISH of MALT1, IGH in a tonsillar extranodal marginal zone lymphoma. A red probe is utilized for MALT1, green probe for $I G H$. Both probes span the breakpoint, resulting in two fusion signals. 
Table 3 Genetic characterization of extranodal marginal zone lymphoma

\begin{tabular}{|c|c|c|c|c|c|}
\hline Case & Age & Sex & Site & $R T-P C R$ & FISH \\
\hline 1 & 24 & M & Soft tissue, scalp & Negative & Normal \\
\hline 2 & 29 & $\mathrm{M}$ & Skin & Negative & Normal \\
\hline 3 & 23 & M & Adenoids & Negative & Normal \\
\hline 4 & 1.5 & $\mathrm{~F}$ & Tonsils & Negative & $\begin{array}{l}\mathrm{t}(14 ; 18) \\
\text { IGH-MALT1 }\end{array}$ \\
\hline 6 & 17 & $\mathrm{~F}$ & Skin, arm & Negative & NA \\
\hline 7 & 27 & M & Skin, back & Negative & Normal \\
\hline 9 & 11 & $\mathrm{M}$ & Conjunctiva & Negative & Normal \\
\hline $10 \mathrm{a}^{\mathrm{a}}$ & 25 & $\mathrm{M}$ & Thyroid & Negative & NA \\
\hline $10 \mathrm{~b}^{\mathrm{a}}$ & & & Adjacent neck LN & Negative & Tetraploidy \\
\hline $11^{\mathrm{a}}$ & 29 & M & $\begin{array}{l}\text { Skin/subcutaneous, } \\
\text { back }\end{array}$ & Negative & Normal \\
\hline $12^{\mathrm{a}}$ & 23 & M & Stomach & Negative & NA \\
\hline $13^{\mathrm{a}}$ & 28 & $\mathrm{~F}$ & Parotid & NA & Normal \\
\hline $14^{\mathrm{a}}$ & 25 & $\mathrm{M}$ & Orbital mass & Negative & Normal \\
\hline $15^{\mathrm{a}}$ & 27 & $\mathrm{~F}$ & Skin, back & Negative & NA \\
\hline $16^{\mathrm{a}}$ & 29 & $\mathrm{~F}$ & Parotid gland \& LN & NA & Normal \\
\hline $17^{\mathrm{a}}$ & 10 & M & Lacrimal sac & Negative & Normal \\
\hline $18^{\mathrm{a}}$ & 17 & $\mathrm{~F}$ & $\begin{array}{l}\text { Submandibular } \\
\text { salivary gland }\end{array}$ & Negative & Normal \\
\hline $19^{\mathrm{a}}$ & 22 & $\mathrm{~F}$ & Conjunctiva & NA & Trisomy 3 \\
\hline
\end{tabular}

${ }^{\mathrm{a}}$ Cases previously reported by Taddesse Heath et al. ${ }^{13}$

Negative, denotes negative for all known breakpoints; N.A., tissue not available for analysis; LN, lymph node.

Table 4 Summary of genetic aberrations

\begin{tabular}{lcc}
\hline & $\begin{array}{c}\text { Nodal marginal } \\
\text { zone lymphoma }\end{array}$ & $\begin{array}{c}\text { Extranodal marginal } \\
\text { zone lymphoma }\end{array}$ \\
\hline $\begin{array}{l}\text { Total cases } \\
\text { Percentage of genetic } \\
\text { aberrations }\end{array}$ & $24 \%(59 \%)$ & $17(41 \%)$ \\
Trisomy 18 & $17 \%(4 / 23)$ & $18 \%(3 / 17)$ \\
Trisomy 3 & $4 \%(1 / 23)$ & $7 \%(1 / 14)$ \\
$\mathrm{t}(I G H)$, unknown & $4 \%(1 / 23)$ & - \\
partner & - & $7 \%(1 / 14)$ \\
$\mathrm{t}(14 ; 18)$ IGH-MALT1 & - & $7 \%(1 / 14)$ \\
Tetraploidy & & \\
\hline
\end{tabular}

and young adult population. Genetic abnormalities were identified in both the nodal and extranodal marginal zone lymphoma cases, albeit at a low frequency (Table 4). Twenty-one percent of the cases of nodal marginal zone lymphomas showed a genetic change, most notably trisomy 18 , seen in four cases $(17 \%)$. The extranodal marginal zone lymphoma cases had a slightly lower incidence of genetic aberrations (18\%). Trisomy 3 and tetraploidy were each seen in one case of extranodal marginal zone lymphoma. Numerical abnormalities of chromosomes 3 and 18 are relatively common in nodal and extranodal marginal zone lymphomas in adults. $^{12}$

Only one case in each cohort showed evidence of an IGH translocation, with MALT1 being the partner in a single case involving the tonsil of a 1.5 -year-old female. Streubel et al showed that the $\mathrm{t}(14 ; 18)$ involving IGH/MALT1 had an incidence of $11 \%$ in extranodal cases analyzed in adults, with the highest frequency seen in the ocular adnexa/orbit $(24 \%){ }^{3}$

The differential diagnosis of marginal zone lymphoma includes atypical marginal zone hyperplasia, which can present in mucosal-associated lymphoid tissue in Waldeyer's ring or small intestine. ${ }^{19}$ In the report by Attygalle et al these cases all showed lambda light chain restriction, but failed to show evidence of clonality at the genetic level by PCR analysis for immunoglobulin heavy chain gene rearrangement. Our current study omitted cases which met these criteria. Seven cases of nodal marginal zone lymphoma expressed lambda, and immunoglobulin heavy chain gene clonality was confirmed in all seven cases. Only one extranodal marginal zone lymphoma expressed lambda, and this case presented as an orbital mass. Thus, we do not believe that a diagnosis of marginal zone hyperplasia is likely in our cases, or can account for the relatively low incidence of genetic aberrations seen. Nevertheless, one should be mindful of the differential diagnosis of marginal zone hyperplasia, which can present in both nodal and extranodal sites. ${ }^{20-22}$

It has been shown that the clinical findings, histological presentation, immunophenotype and genetic aberrations of certain lymphomas differ between the adult and pediatric population. ${ }^{23-26} \mathrm{~A}$ recent review and synopses from the society of Hematopathology/European Association Haematopathology workshop illustrated these differences. ${ }^{23}$ Follicular lymphoma differs in the clinical, histological and immunophenotypical presentation between adults and pediatric patients. Pediatric follicular lymphoma cases are usually localized and curable, and may involve extranodal sites, including the testis. ${ }^{24,25}$ Histologically, they are more often grade 2 or 3 and a majority of them lack BCL-2 by immunohistochemical staining and BCL2 gene rearrangements.

The previous study by Taddesse-Heath et al analyzed the clinical and histological presentation of marginal zone lymphomas in young adults and children and found distinct characteristics not appreciated in the adult population. ${ }^{13}$ Our expanded study confirms previously reported features with nodal marginal zone lymphomas being more common than extranodal marginal zone lymphomas in this age group. This is in contrast to the adult population where extranodal marginal zone lymphomas is much more common than nodal marginal zone lymphomas. ${ }^{1}$ An excess of males over females was seen in both groups, contrasting with the usual female predominance seen typically in extranodal marginal zone lymphomas. ${ }^{2}$ For nodal marginal zone lymphomas the incidence in male and female patients is generally equal in the adult population. ${ }^{27-29}$

Table 5 summarizes the clinical features of previously reported cases and cases identified since 
Table 5 Summary of the clinical characteristics at presentation including newly identified cases and those reported previously by Taddesse $e t a l^{13}$

\begin{tabular}{llc}
\hline & $\begin{array}{l}\text { Nodal marginal } \\
\text { zone lymphoma }\end{array}$ & $\begin{array}{c}\text { Extranodal marginal } \\
\text { zone lymphoma }\end{array}$ \\
\hline Incidence & $62 \%$ (39 total cases) & $38 \%$ (24 total cases) \\
Median age & 16 years old & 23 years old \\
Overall M/F & $7: 1$ & $1.7: 1$ \\
Cases $\leq 18$ years old & $72 \%(28 / 39)$ & $38 \%(9 / 24)$ \\
M/F (<18 years) & $13: 1$ & $1.3: 1$ \\
Common sites & Cervical: $49 \%$ & Skin/soft tissue: $29 \%$ \\
& Inguinal: $13 \%$ & Conjunctiva: $13 \%$ \\
& Submandibular: $10 \%$ & Orbital: $13 \%$ \\
& Periparotid: $8 \%$ & Parotid: $13 \%$
\end{tabular}

our previous report. Almost half of the nodal marginal zone lymphoma cases presented in cervical lymph nodes, with another $10 \%$ in submandibular lymph nodes. Inguinal lymph node involvement was seen in $13 \%$ of patients. There was a marked male predominance, which was even more striking in patients under the age of 18, where the male/female ratio was 13:1. The extranodal marginal zone lymphoma cases showed a higher median age of presentation when compared with nodal marginal zone lymphomas, 23 vs 16 years. The most common site of involvement was the skin and soft tissue, seen in $28 \%$ of the cases. Two of the extranodal marginal zone lymphoma cases had involvement of adjacent lymph nodes. ${ }^{13}$

Marginal zone lymphomas lack a specific immunoprofile, but immunohistochemical studies still provide some useful information. Co-expression of CD43 was seen in a majority of nodal and extranodal marginal zone lymphoma cases (88 and $80 \%$, respectively). BCL-2 positivity by immunohistochemistry was seen in over half of the nodal and extranodal marginal zone lymphoma cases and IgD was positive in a minority of the cases $(20 \%)$. Light chain restriction could be shown in $70 \%$ of cases. However, it is preferable to confirm clonality by PCR for immunoglobulin gene rearrangement, and PCR studies are in fact more sensitive. IGk probe analysis is particularly useful for study of DNA extracted from paraffin blocks, as the quality of the DNA in such samples often does not permit use of framework 2 probes, requiring DNA fragments of larger size.

Our study is the first to analyze genetic aberrations in nodal marginal zone lymphomas and extranodal marginal zone lymphomas occurring in the pediatric and young adult population. This larger cohort of cases confirms our previous observations regarding clinicopathological features. Although the number of cases with aberrations was small, we detected no clinical differences in the cases with and without aberrations. The optimal clinical management for marginal zone lymphoma in this age group remains to be determined.
Unfortunately, the nature of this referral population did not allow examination of long-term follow-up; however, local recurrence was reported in only one case.

\section{Disclosure/conflict of interest}

The authors declare no conflict of interest.

\section{References}

1 Swerdlow SH, Campo E, Harris NL, et al. WHO classification of Tumours of Haematopoietic and Lymphoid Tissues, 4th edn. International Agency for Research on Cancer: Lyon, France, 2008.

2 Isaacson PG, Du MQ. MALT lymphoma: from morphology to molecules. Nat Rev Cancer 2004;4:644-653.

3 Streubel B, Simonitsch-Klupp I, Mullauer L, et al. Variable frequencies of MALT lymphoma-associated genetic aberrations in MALT lymphomas of different sites. Leukemia 2004;18:1722-1726.

4 Liu H, Ruskon-Fourmestraux A, Lavergne-Slove A, et al. Resistance of $\mathrm{t}(11 ; 18)$ positive gastric mucosaassociated lymphoid tissue lymphoma to Helicobacter pylori eradication therapy. Lancet 2001;357:39-40.

5 Liu H, Ye H, Ruskone-Fourmestraux A, et al. T(11;18) is a marker for all stage gastric MALT lymphomas that will not respond to H. pylori eradication. Gastroenterology 2002;122:1286-1294.

6 Remstein ED, Dogan A, Einerson RR, et al. The incidence and anatomic site specificity of chromosomal translocations in primary extranodal marginal zone B-cell lymphoma of mucosa-associated lymphoid tissue (MALT lymphoma) in North America. Am J Surg Pathol 2006;30:1546-1553.

7 Aamot HV, Micci F, Holte $\mathrm{H}$, et al. G-banding and molecular cytogenetic analyses of marginal zone lymphoma. Br J Haematol 2005;130:890-901.

8 Ferreira BI, Garcia JF, Suela J, et al. Comparative genome profiling across subtypes of low-grade B-cell lymphoma identifies type-specific and common aberrations that target genes with a role in B-cell neoplasia. Haematologica 2008;93:670-679.

9 Brynes RK, Almaguer PD, Leathery KE, et al. Numerical cytogenetic abnormalities of chromosomes 3,7 , and 12 in marginal zone B-cell lymphomas. Mod Pathol 1996;9:995-1000.

10 Dierlamm J. Genetic abnormalities in marginal zone B-cell lymphoma. Haematologica 2003;88:8-12.

11 Dierlamm J, Michaux L, Wlodarska I, et al. Trisomy 3 in marginal zone B-cell lymphoma: a study based on cytogenetic analysis and fluorescence in situ hybridization. Br J Haematol 1996;93:242-249.

12 Dierlamm J, Pittaluga S, Wlodarska I, et al. Marginal zone B-cell lymphomas of different sites share similar cytogenetic and morphologic features. Blood 1996; 87:299-307.

13 Taddesse-Heath L, Pittaluga S, Sorbara L, et al. Marginal zone B-cell lymphoma in children and young adults. Am J Surg Pathol 2003;27:522-531.

14 Elenitoba-Johnson KS, Kumar S, Lim MS, et al. Marginal zone B-cell lymphoma with monocytoid B-cell lymphocytes in pediatric patients without 
immunodeficiency. A report of two cases. Am J Clin Pathol 1997;107:92-98.

15 Ramasamy I, Brisco M, Morley A. Improved PCR method for detecting monoclonal immunoglobulin heavy chain rearrangement in B cell neoplasms. J Clin Pathol 1992;45:770-775.

16 Inagaki H, Okabe M, Seto M, et al. API2-MALT1 fusion transcripts involved in mucosa-associated lymphoid tissue lymphoma: multiplex RT-PCR detection using formalin-fixed paraffin-embedded specimens. Am J Pathol 2001;158:699-706.

17 Streubel B, Lamprecht A, Dierlamm J, et al. $\mathrm{T}(14 ; 18)(\mathrm{q} 32 ; \mathrm{q} 21)$ involving IGH and MALT1 is a frequent chromosomal aberration in MALT lymphoma. Blood 2003;101:2335-2339.

18 Vinatzer U, Gollinger M, Mullauer L, et al. Mucosaassociated lymphoid tissue lymphoma: novel translocations including rearrangements of ODZ2, JMJD2C, and CNN3. Clin Cancer Res 2008;14:6426-6431.

19 Attygalle AD, Liu H, Shirali S, et al. Atypical marginal zone hyperplasia of mucosa-associated lymphoid tissue: a reactive condition of childhood showing immunoglobulin lambda light-chain restriction. Blood 2004;104:3343-3348.

20 Meda BA, Frost M, Newell J, et al. BCL-2 is consistently expressed in hyperplastic marginal zones of the spleen, abdominal lymph nodes, and ileal lymphoid tissue. Am J Surg Pathol 2003;27:888-894.

21 Hunt JP, Chan JA, Samoszuk M, et al. Hyperplasia of mantle/marginal zone B cells with clear cytoplasm in peripheral lymph nodes. A clinicopathological study of 35 cases. Am J Clin Pathol 2001;116:550-559.

22 Guitart J, Gerami P. Is there a cutaneous variant of marginal zone hyperplasia? Am J Dermatopathol 2008;30:494-496.

23 Swerdlow SH. Pediatric follicular lymphomas, marginal zone lymphomas, and marginal zone hyperplasia. Am J Clin Pathol 2004;122(Suppl):S98-S109.

24 Lorsbach RB, Shay-Seymore D, Moore J, et al. Clinicopathological analysis of follicular lymphoma occurring in children. Blood 2002;99:1959-1964.

25 Finn LS, Viswanatha DS, Belasco JB, et al. Primary follicular lymphoma of the testis in childhood. Cancer 1999;85:1626-1635.

26 Pileri SA, Sabattini E, Rosito P, et al. Primary follicular lymphoma of the testis in childhood: an entity with peculiar clinical and molecular characteristics. J Clin Pathol 2002;55:684-688.

27 Berger F, Felman P, Thieblemont C, et al. Non-MALT marginal zone B-cell lymphomas: a description of clinical presentation and outcome in 124 patients. Blood 2000;95:1950-1956.

28 Traverse-Glehen A, Felman P, Callet-Bauchu E, et al. A clinicopathological study of nodal marginal zone B-cell lymphoma. A report on 21 cases. Histopathology 2006;48:162-173.

29 Camacho FI, Algara P, Mollejo M, et al. Nodal marginal zone lymphoma: a heterogeneous tumor: a comprehensive analysis of a series of 27 cases. Am J Surg Pathol 2003;27:762-771. 